\title{
Preferensi dan tanggap fungsional Neoseiulus californicus McGregor (Acari: Phytoseiidae) sebagai predator Tetranychus kanzawai Kishida (Acari: Tetranychidae)
}

\author{
Preference and functional response of Neoseiulus californicus \\ McGregor (Acari: Phytoseiidae) as predator of Tetranychus kanzawai \\ Kishida (Acari: Tetranychidae)
}

Sugeng Santoso*, Edwin Iswella

Departemen Proteksi Tanaman, Fakultas Pertanian, Institut Pertanian Bogor Jalan Kamper, Kampus IPB Darmaga, Bogor 16680

(diterima Januari 2013, disetujui Mei 2013)

\begin{abstract}
ABSTRAK
Tungau laba-laba kanzawa (TLK), Tetranychus kanzawai Kishida (Acari: Tetranychidae) merupakan hama penting pada berbagai jenis tanaman di Indonesia. Pengendalian tungau ini umumnya dilakukan menggunakan akarisida, yang bisa menimbulkan dampak samping negatif. Salah satu alternatif cara pengendalian yang aman adalah dengan tungau predator. Penelitian ini bertujuan untuk mengetahui preferensi dan tanggap fungsional tungau predator Neoseiulus californicus McGregor (Acari: Phytoseiidae) terhadap beberapa stadia TLK. Penelitian dilakukan di laboratorium pada suhu ruang. $N$. californicus diberi mangsa telur dan nimfa TLK untuk mengetahui preferensinya. $N$. californicus juga diberi mangsa telur TLK pada beberapa tingkat kepadatan untuk mengetahui tanggap fungsionalnya. Imago betina dan deutonimfa $N$. californicus lebih memilih telur dibandingkan nimfa TLK. Jumlah telur yang dikonsumsi oleh imago betina dan deutonimfa $N$. californicus meningkat dengan meningkatnya kepadatan mangsa. Jumlah telur yang diletakkan imago betina $N$. californicus semakin meningkat dengan meningkatnya kepadatan mangsa. Waktu pencarian mangsa oleh imago betina dan deutonimfa $N$. californicus semakin cepat dengan meningkatnya kepadatan mangsa yang diberikan. Pada populasi mangsa yang rendah $N$. californicus bisa memangsa sesamanya.
\end{abstract}

Kata kunci: Neoseiulus californicus, tanggap fungsional, preferensi mangsa

\begin{abstract}
Kanzawa spider mite (KSM), Tetranychus kanzawai Kishida (Acari: Tetranychidae) is an important pest on many crops in Indonesia. Generally, farmers use acaricide to control this mite, which may cause negative side effects. One of the alternative control methods is the use of predatory mite. This research was done to determine prey preference and functional response of predatory mite Neoseiulus californicus (Acari: Phytoseiidae) on several life stages of KSM. Experiments were conducted under laboratory conditions. $N$. californicus were supplied with nymphs and adults of KSM to know its preference. $N$. californicus were also supplied with KSM eggs at several densities to know its functional response. Adult females and deutonymphs of $N$. californicus preferred KSM eggs than nymphs as their prey. The number of eggs consumed by adult females and deutonymphs $N$. californicus increased with the increase of prey density. The number of eggs laid by adult females of $N$. californicus increased with the increase of prey density. Searching time of the predator became
\end{abstract}

\footnotetext{
*Penulis korespondensi: Sugeng Santoso. Departemen Proteksi Tanaman, Fakultas Pertanian, Institut Pertanian Bogor,

Jalan Kamper, Kampus IPB Darmaga Bogor 16680

Tel: 0251-8629364, Faks: 0251-8629362, Email: soe3toso@yahoo.com
} 
faster with the increase of prey density. N. californicus showed cannibalism under low density of prey.

Key words: Neoseiulus californicus, functional response, prey preference

\section{PENDAHULUAN}

Tungau laba-laba Kanzawa (TLK), Tetranychus kanzawai Kishida (Acari: Tetranychidae), banyak menyebabkan kerugian pada berbagai tanaman pertanian di Indonesia. Pada umumnya pengendalian tungau ini dilakukan secara kimiawi dengan akarisida. Pengendalian tungau laba-laba secara kimiawi bisa menyebabkan terjadinya resistensi terhadap akarisida dalam beberapa tahun (Gotoh et al. 2004). Pada tahun 1987 di Australia dilaporkan Tetranychus urticae Koch pada pertanaman mawar di rumah kaca menjadi resisten terhadap clofentezine diaplikasi sebanyak 40 kali selama lebih dari sepuluh bulan (Dixon 2000).

Dalam rangka menghindari dampak negatif pengendalian tungau secara kimiawi, pemanfaatan musuh alami menjadi alternatif terbaik. Tungau predator dari famili Phytoseiidae telah diketahui menjadi musuh alami yang sangat penting bagi tungau laba-laba (Gotoh et al. 2004). Toyoshima \& Hinomoto (2004) menyatakan bahwa famili Phytoseiidae telah mendapat perhatian yang sangat besar dan beberapa jenisnya telah dimanfaatkan untuk pengendalian di lapangan. Di Jepang, Phytoseiulus persimilis Athias-Henriot diketahui efektif dalam mengendalikan populasi T. kanzawai pada tanaman anggur di rumah kaca yang tidak diberi perlakuan pestisida dalam skala luas. Di Taiwan, Neoseiulus fallacis Garmen dan $P$. persimilis dilaporkan efektif dalam mengendalikan TLK setelah diintroduksikan pada tanaman teh di rumah kaca dengan perbandingan predator: mangsa adalah 1:20 (Zhang 2003).

Tungau predator famili Phytoseiidae mempunyai sifat dapat bertahan dan berkembang pada kepadatan mangsa yang rendah (McMurty \& Rodriguez 1987). Pada populasi tungau laba-laba yang tinggi, tungau predator famili Phytoseiidae memiliki kemampuan menekan populasinya dengan kemampuan adaptasi dan reproduksinya (Gotoh et al. 2004). Genus-genus dalam Phytoseiidae yang merupakan predator tungau laba-laba diantaranya adalah Neoseiulus dan Phytoseiulus. N. californicus merupakan tungau predator dari famili Phytoseiidae yang telah dikenal luas di seluruh dunia (Toyoshima \& Hinomoto 2004). Tungau predator ini membutuhkan sedikit mangsa dan memiliki potensi kanibalisme yang rendah, kisaran mangsa luas dengan kemampuan dan aktivitas pencarian serta reproduksi tinggi sehingga dapat mengatur kepadatan populasi mangsa pada tingkat yang rendah (Toyoshima \& Hinomoto 2004). Di Indonesia, penelitian tentang potensi $N$. californicus sebagai predator TLK belum pernah dilakukan sehingga penelitian ini akan memberikan informasi baru yang sangat penting.

Tujuan penelitian ini adalah untuk mengetahui preferensi mangsa dan tanggap fungsional tungau predator $N$. californicus terhadap beberapa stadia mangsa TLK, serta kemungkinan terjadinya kanibalisme.

\section{BAHAN DAN METODE}

Penelitian dilaksanakan di Laboratorium Ekologi Serangga, Departemen Proteksi Tanaman, Fakultas Pertanian, Institut Pertanian Bogor dari bulan Juni 2007 sampai dengan Agustus 2007.

\section{Pemeliharaan TLK dan $N$. californicus}

Arena pemeliharaan adalah cawan petri $(\varnothing=$ $6 \mathrm{~cm}$ ), yang di dalamnya secara berurutan diletakkan busa ( $\varnothing=5,5 \mathrm{~cm})$, kapas $(5 \mathrm{~cm} \mathrm{x} 4 \mathrm{~cm})$, dan daun kacang merah. Busa dan kapas selalu dijenuhi dengan air untuk menjaga kesegaran daun kacang merah dan mencegah tungau keluar dari arena percobaan.

TLK diambil dari pertanaman stroberi di daerah Cipanas dan dipelihara pada arena pemeliharaan. Daun kacang merah pada arena pemeliharaan diganti setiap tiga hari. Pembiakan massal TLK juga dilakukan pada tanaman kacang merah yang ditanam dalam polibag. Tungau predator $N$. californicus dipelihara dan diperbanyak pada arena percobaan yang berisi TLK. Setiap tiga hari tungau predator ini dipindahkan ke arena pemeliharaan yang baru agar berkembang biak. 
Preferensi N. californicus terhadap stadia TLK

Arena percobaan adalah cawan petri $(\varnothing=$ $6 \mathrm{~cm}$ ), yang di dalamnya secara berurutan diletakkan busa $(\varnothing=5,5 \mathrm{~cm})$, kapas $(5 \mathrm{~cm} \times 4 \mathrm{~cm})$, dan daun kacang merah $(2 \mathrm{~cm} \times 2 \mathrm{~cm})$. Busa dan kapas selalu dijenuhi dengan air untuk menjaga kesegaran daun kacang merah dan mencegah tungau keluar dari arena percobaan.

Uji preferensi mangsa dilakukan untuk imago betina dan deutonimfa $N$. californicus. Mangsa yang digunakan adalah telur dan nimfa TLK. Pada arena percobaan berukuran $2 \mathrm{~cm} \times 2 \mathrm{~cm}$ diletakkan masing-masing 20 butir telur dan 20 individu nimfa TLK. Ke dalam arena percobaan dimasukkan masing-masing 1 individu $N$. californicus yang telah dipuasakan selama 6 jam. Predator dibiarkan selama 24 jam di dalam arena percobaan. Jumlah telur dan nimfa TLK yang dimangsa kemudian dihitung. Masing-masing perlakuan percobaan diulang 10 kali.

\section{Tanggap fungsional $N$. californicus terhadap TLK}

Uji tanggap fungsional dilakukan pada arena percobaan serupa dengan uji preferensi mangsa. Uji tanggap fungsional fungsional $N$. californicus dilaksanakan dengan menggunakan telur TLK sebagai mangsa. Stadia predator yang digunakan adalah imago betina dan deutonimfa. Ke dalam arena percobaan yang berisi telur TLK dengan kepadatan 5, 10, 20, 40, dan 60 telur, masingmasing ditempatkan 1 individu imago betina atau deutonimfa $N$. californicus yang telah dipuasakan selama 6 jam. Setelah 24 jam, jumlah telur TLK yang dimangsa oleh predator diamati dengan menghitung jumlah telur yang tersisa. Selain itu, jumlah telur yang diletakkan oleh imago betina predator juga dihitung. Percobaan diulang 10 kali.

\section{Waktu pencarian dan penanganan oleh $N$. californicus pada berbagai kepadatan TLK}

Percobaan ini dilakukan pada arena percobaan yang serupa dengan uji preferensi mangsa. Stadia $N$. californicus yang digunakan dalam percobaan ini adalah imago betina dan deutonimfa. Mangsa yang digunakan dalam percobaan ini adalah nimfa TLK. Ke dalam arena percobaan dimasukkan nimfa TLK dengan jumlah 5, 10, 15, dan 20 individu. Ke dalam setiap arena percobaan kemudian dimasukkan 1 individu imago betina atau deutonimfa tungau $N$. californicus yang telah dipuasakan selama 6 jam. Waktu yang dibutuhkan predator sejak dimasukkan sampai mendapatkan mangsanya yang pertama diamati dan dicatat. Selain itu, waktu yang dibutuhkan predator untuk menghabiskan 1 individu mangsa juga diamati dan dicatat. Masing-masing perlakuan percobaan diulang 10 kali.

\section{Potensi terjadinya kanibalisme pada $N$. californicus}

Percobaan ini dilakukan pada arena percobaan yang serupa dengan uji preferensi mangsa. Stadia predator yang digunakan adalah imago betina dan deutonimfa $N$. californicus. Ke dalam arena percobaan yang berisi 10 nimfa tungau merah dimasukkan deutonimfa, imago betina atau campuran $(1: 1)$ antara deutonimfa dengan imago betina tungau predator yang sudah dipuasakan selama 6 jam dengan kepadatan 2, 4, 6 , dan 8 individu predator. Pengamatan potensi kanibalisme dilakukan 24 jam setelah perlakuan dengan mencatat jumlah mangsa dan predator yang hilang atau rusak karena dimangsa predator lain. Masing-masing perlakuan percobaan diulang 10 kali.

\section{HASIL}

\section{Preferensi $N$. californicus terhadap stadia TLK}

Bahwa, baik imago betina maupun deutonimfa predator $N$. californicus lebih memilih stadia telur T. kanzawai sebagai mangsa dibandingkan dengan stadia nimfa (Gambar 1). Jumlah telur yang dimangsa deutonimfa dan imago betina predator masing-masing adalah 10,75 $\pm 5,00$ dan $14,90 \pm 4,87$ telur, lebih tinggi dibandingkan dengan jumlah nimfa yang dimangsa dalam waktu yang sama, yaitu berturut-turut $6,30 \pm 3,61$; $9,45 \pm 4,41$ individu. Imago betina predator bisa mengkonsumsi mangsa, baik telur maupun nimfa T. kanzawai, dalam jumlah yang lebih banyak dibandingkan dengan deutonimfa.

\section{Tanggap fungsional $N$. californicus terhadap TLK}

Secara umum, jumlah telur yang dikonsumsi oleh imago betina dan deutonimfa $N$. californicus 
semakin meningkat dengan meningkatnya kepadatan mangsa (Tabel 1). Rataan tertinggi jumlah telur yang dimangsa oleh deutonimfa $N$ californicus terjadi pada kepadatan mangsa 40 dan 60 telur, yaitu sebesar 29,60 $\pm 5,50$ individu dan $29,00 \pm 5,14$ individu, lebih tinggi dibandingkan dengan kepadatan mangsa lainnya, sedangkan rataan tertinggi jumlah telur yang dimangsa oleh imago betina $N$. californicus terjadi pada kepadatan 60 telur, yaitu sebanyak 39,80 $\pm 12,00$ telur, lebih tinggi dibandingkan dengan kepadatan mangsa yang lainnya.

Gambar 2A menunjukkan hubungan antara peningkatan kepadatan mangsa dan peningkatan jumlah mangsa yang dikonsumsi. Meskipun peningkatan kepadatan mangsa menyebabkan peningkatan jumlah mangsa yang dikonsumsi, namun secara proporsi terjadi hal sebaliknya. Gambar 2B menunjukkan hubungan yang nyata antara peningkatan kepadatan mangsa dan penurunan proporsi mangsa yang dikonsumsi. Selain meningkatkan jumlah mangsa yang dikonsumsi, kepadatan mangsa juga mempengaruhi jumlah telur yang diletakkan oleh imago betina predator per hari (Gambar 2C).

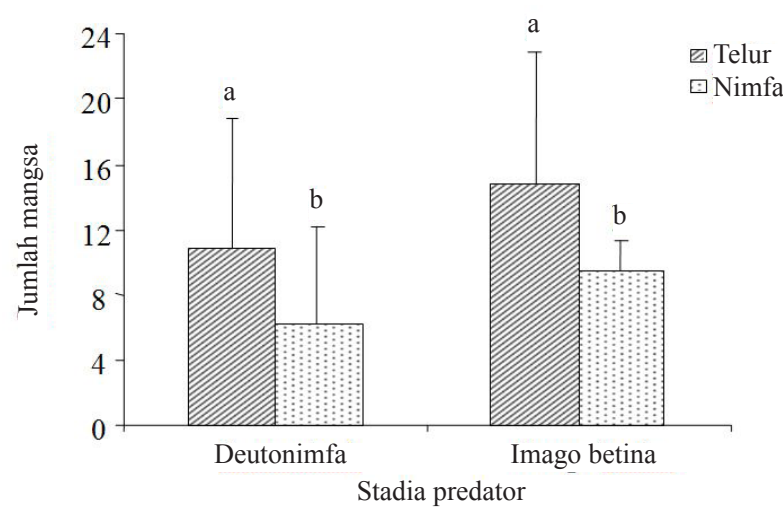

Gambar 1. Preferensi Neoseiulus californicus terhadap stadia TLK yang berbeda.

Tabel 1. Pemangsaan oleh Neoseiulus californicus pada berbagai kepadatan TLK

\begin{tabular}{lcr}
\hline Kepadatan & \multicolumn{2}{c}{ Jumlah telur yang dimangsa predator $\pm \mathrm{SD}^{\mathrm{a}}$} \\
\cline { 2 - 3 } TLK & \multicolumn{1}{c}{$\mathrm{x} \pm \mathrm{SD}$} & $\mathrm{N}$ \\
\hline 5 & $4,58 \pm 0,66 \mathrm{c}$ & $4,66 \pm 1,15 \mathrm{c}$ \\
10 & $8,25 \pm 2,00 \mathrm{bc}$ & $9,08 \pm 2,27 \mathrm{c}$ \\
20 & $12,08 \pm 5,97 \mathrm{~b}$ & $15,83 \pm 4,56 \mathrm{~b}$ \\
40 & $29,60 \pm 5,50 \mathrm{a}$ & $35,80 \pm 7,19 \mathrm{a}$ \\
60 & $29,00 \pm 5,14 \mathrm{a}$ & $39,80 \pm 12,50 \mathrm{a}$
\end{tabular}

${ }^{a}$ Rataan dalam kolom yang diikuti oleh huruf yang sama tidak berbeda nyata pada uji Duncan, $\alpha=0,05$.
Peningkatan kepadatan mangsa dari 20 menjadi 60 , meningkatkan rata-rata jumlah telur yang diletakkan oleh imago betina tungau predator dari 0,75 menjadi 1,3 butir per hari.

\section{Waktu pencarian dan penanganan oleh $N$. californicus pada berbagai kepadatan TLK}

Waktu pencarian oleh imago betina $N$. californicus secara umum lebih cepat dibandingkan dengan deutonimfa (Tabel 2). Waktu pencarian mangsa oleh imago betina $N$. californicus umumnya berfluktuasi. Waktu pencarian mangsa terlama imago $N$. californicus pada kepadatan 5 individu, yaitu 15,20 $\pm 11,96$ menit, sedangkan yang tercepat pada kepadatan 20 individu selama $4,00 \pm 2,54$ menit. Pada kepadatan 5 individu mangsa, deutonimfa membutuhkan waktu terlama rata-rata $20,00 \pm 19,54$ menit untuk dapat menemukan mangsa dan yang tercepat $6,20 \pm 2,48$ menit pada kepadatan 15 individu mangsa. Masa
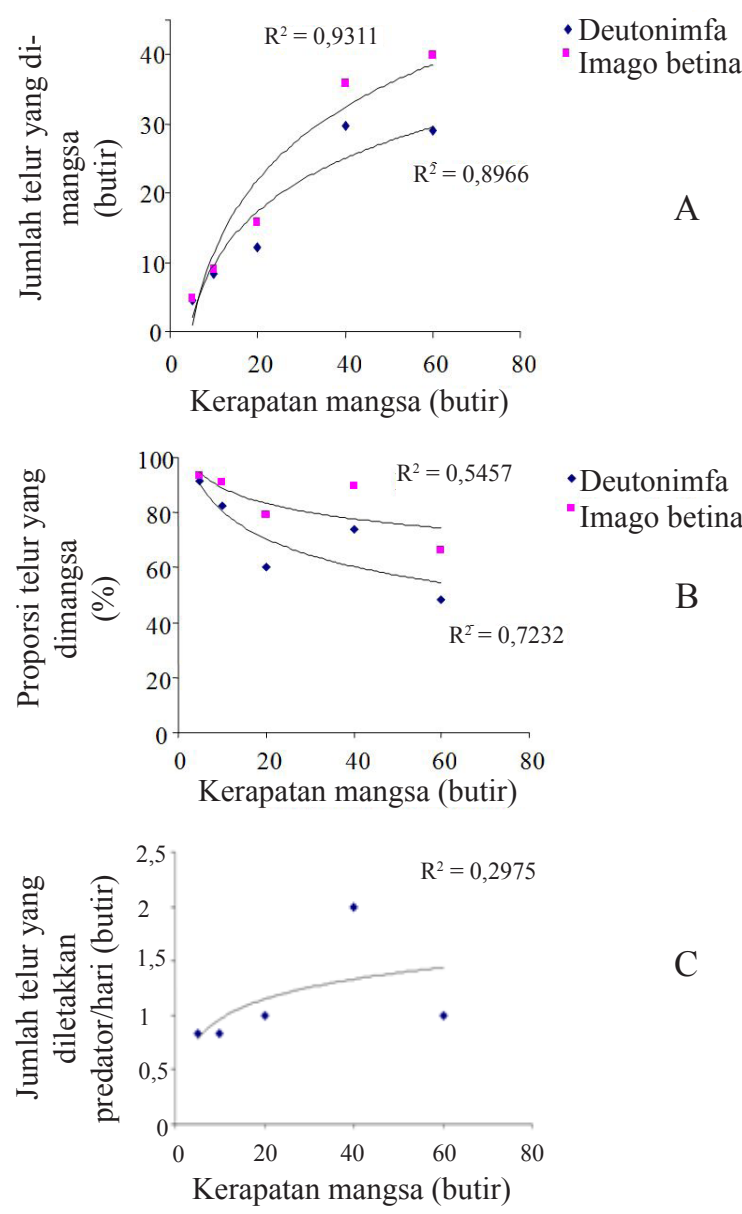

Gambar 2. Tanggap fungsional Neoseiulus californicus: A: jumlah telur TLK yang dimangsa; B: proporsi telur TLK yang dimangsa; dan C: jumlah telur N. californicus yang diletakkan. 
penanganan mangsa oleh deutonimfa rata-rata berkisar antara 5,60 $\pm 2,19$ menit sampai 7,80 \pm 4,08 menit, cenderung lebih panjang dibandingkan dengan imago betina yang bisa menangani mangsa dalam waktu 2,60 $\pm 0,89$ menit sampai dengan $6,20 \pm 1,92$ menit.

\section{Potensi terjadinya kanibalisme pada $N$. californicus}

Dalam kondisi kepadatan mangsa rendah dan kepadatan predator tinggi, N. californicus menunjukkan potensi kanibalisme. Kanibalisme terjadi baik antar predator dengan stadia yang sama, maupun antara stadia yang berbeda. Pada perlakuan stadia yang sama, 2,40 $\pm 0,96$ individu deutonimfa dimangsa oleh sesamanya. Fenomena ini terjadi pada kepadatan 8 individu predator. Sebaliknya, pada kepadatan 2 individu predator tidak terjadi kanibalisme (Tabel 3). Pada kondisi yang sama, $1,20 \pm 1,03$ imago predator dimangsa oleh sesamanya pada kepadatan 6 individu predator. Pada kondisi campuran, jumlah predator yang dimangsa sesamanya semakin meningkat dengan meningkatnya kepadatan predator. Jumlah deutonimfa $N$. californicus yang dimangsa imagonya pada kepadatan 8 individu adalah sebesar 1,50 $\pm 1,08$ individu, lebih tinggi dibandingkan dengan kepadatan lainnya. Sebaliknya, jumlah imago betina $N$. californicus yang dimangsa deutonimfa tidak berbeda nyata antar kepadatan predator. Jumlah deutonimfa yang dimangsa oleh imago lebih tinggi dibandingkan dengan imago yang dimangsa oleh deutonimfa.

\section{PEMBAHASAN}

Baik deutonimfa maupun imago betina predator $N$. californicus lebih memilih stadia telur

Tabel 2. Waktu pencarian dan masa penanganan oleh Neoseiulus californicus pada berbagai tingkat kepadatan TLK

\begin{tabular}{lcrrrr}
\hline Kepadatan & \multicolumn{2}{c}{ Waktu pencarian (menit) } & & \multicolumn{2}{c}{ Waktu penanganan (menit) } \\
\cline { 2 - 3 } \cline { 5 - 6 } TLK & Imago betina & Deutonimfa & & Imago betina & Deutonimfa \\
\hline 5 & $15,20 \pm 11,96$ & $20,00 \pm 19,54$ & & $6,20 \pm 1,92$ & $6,00 \pm 3,16$ \\
10 & $5,80 \pm 3,63$ & $15,60 \pm 13,99$ & & $3,40 \pm 1,34$ & $7,80 \pm 4,08$ \\
15 & $7,20 \pm 2,77$ & $6,20 \pm 2,48$ & & $5,00 \pm 2,82$ & $6,20 \pm 1,09$ \\
20 & $4,00 \pm 2,54$ & $6,40 \pm 3,13$ & & $2,60 \pm 0,89$ & $5,60 \pm 2,19$ \\
\hline
\end{tabular}

Tabel 3. Kanibalisme inter- dan antar stadia pada berbagai kepadatan Neoseiulus californicus

\begin{tabular}{llcccc}
\hline \multirow{2}{*}{$\begin{array}{l}\text { Kepadatan } \\
N . \text { californicus }\end{array}$} & \multicolumn{2}{c}{$\begin{array}{c}\text { Jumlah imago betina/deutonimfa yang } \\
\text { dimangsa oleh sesamanya (ekor) }\end{array}$} & & \multicolumn{2}{c}{$\begin{array}{c}\text { Jumlah imago betina/deutonimfa yang dimangsa } \\
\text { oleh stadia predator yang lain (ekor) }\end{array}$} \\
\cline { 2 - 3 } & Imago betina & Deutonimfa & & Imago betina & Deutonimfa \\
\hline 2 & $0,10 \pm 0,31 \mathrm{~b}$ & $0,00 \pm 0,00 \mathrm{~b}$ & & $0,00 \pm 0,00 \mathrm{a}$ & $0,10 \pm 0,31 \mathrm{c}$ \\
4 & $0,40 \pm 0,51 \mathrm{ab}$ & $0,30 \pm 0,67 \mathrm{~b}$ & & $0,10 \pm 0,31 \mathrm{a}$ & $0,70 \pm 0,48 \mathrm{bc}$ \\
6 & $1,20 \pm 1,03 \mathrm{a}$ & $1,80 \pm 1,22 \mathrm{a}$ & & $0,20 \pm 0,42 \mathrm{a}$ & $1,20 \pm 0,91 \mathrm{ab}$ \\
8 & $1,00 \pm 1,24 \mathrm{a}$ & $2,40 \pm 0,96 \mathrm{a}$ & & $0,20 \pm 0,42 \mathrm{a}$ & $1,50 \pm 1,08 \mathrm{a}$ \\
\hline
\end{tabular}

${ }^{a}$ Rataan dalam kolom yang diikuti oleh huruf yang sama tidak berbeda nyata pada uji Duncan, $\alpha=0,05$
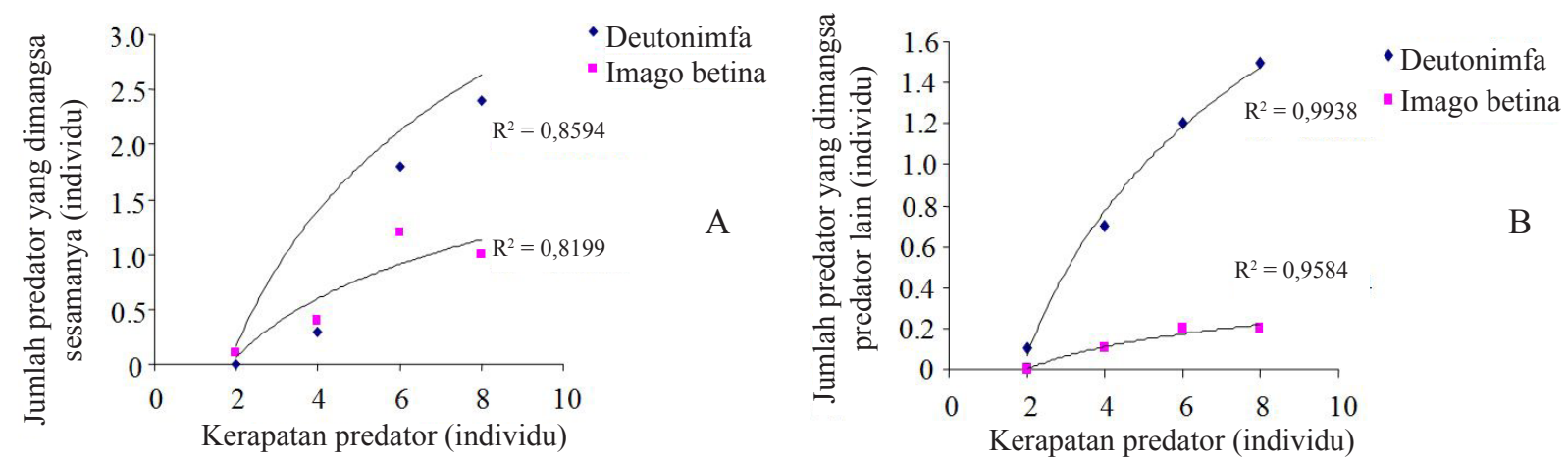

Gambar 3. Hubungan antara peningkatan kepadatan Neoseiulus californicus dengan kanibalisme: A: dalam stadia yang sama; dan B: antar stadia yang berbeda. 
TLK sebagai mangsa dibandingkan stadia nimfa. Hal ini diduga karena predator lebih mudah dalam menemukan dan menangani mangsa yang berupa telur. Telur lebih mudah ditemukan karena tidak bergerak dan lebih mudah ditangani karena tidak mempunyai kemampuan untuk mengadakan perlawanan. Imago betina mempunyai kemampuan memangsa yang lebih tinggi dibandingkan dengan deutonimfa. Hal ini disebabkan, selain mempunyai ukuran tubuh yang lebih besar, imago betina membutuhkan makan yang lebih banyak karena diperlukan untuk pembentukan telur.

Secara umum, jumlah telur yang dikonsumsi oleh imago betina dan deutonimfa $N$. californicus semakin meningkat dengan meningkatnya kepadatan mangsa. Hasil penelitian Canlas et al. (2006) menunjukkan bahwa jumlah telur, larva, dan nimfa $T$. urticae yang dikonsumsi oleh imago betina $N$. californicus meningkat secara eksponensial pada saat diberikan mangsa dengan kepadatan 5-30. Dalam penelitian ini jumlah telur TKL yang dimangsa oleh deutonimfa maupun imago $N$. californicus meningkat secara konstan dengan meningkatnya kepadatan mangsa, dan kemudian mengalami penurunan. Hasil penelitian ini sesuai dengan Gotoh et al. (2004) yang menyatakan bahwa N. californicus, Scolothrips takahashii Priesner dan Stethorus javonicus memiliki tipe tanggap fungsional tipe II. Pada model tanggap fungsional tipe II, laju pemangsaan meningkat secara konstan kemudian menurun ketika populasi mangsa meningkat dan predator mendekati rasa kenyang. Sebagian besar arthopoda mempunyai tanggap fungsional tipe II (Holling 1961; Hassel 1978).

Jumlah telur yang mampu dimangsa oleh imago betina $N$. californicus lebih tinggi dibandingkan dengan deutonimfa $N$. californicus. Hal ini diduga berkaitan dengan kebutuhan energi imago betina yang lebih tinggi dibandingkan dengan deutonimfa A californicus, khususnya ketika imago betina pada masa praoviposisi dan oviposisi. Persentase jumlah telur yang mampu dimangsa deutonimfa dan imago betina semakin menurun dengan meningkatnya kepadatan mangsa. Hal ini menujukkan bahwa terdapat jumlah maksimal mangsa yang dapat dikonsumsi oleh predator dalam satu hari.
Jumlah telur yang diletakkan imago betina $N$. californicus semakin tinggi dengan meningkatnya kepadatan mangsa. Hal ini menunjukkan bahwa predator memiliki kemampuan untuk merespon laju perkembangan mangsanya. Hasil penelitian ini sesuai dengan penelitian Canlas et al. (2006) yang menyatakan bahwa jumlah telur yang diletakkan imago betina $N$. californicus yang diberi makan telur, larva dan nimfa T. urticae semakin meningkat seiring dengan peningkatan kepadatan mangsa.

Waktu pencarian mangsa oleh imago betina $N$. californicus secara umum lebih cepat dibandingkan dengan deutonimfa. Menurut Huffaker \& Messenger (1976), predator melakukan pencarian mangsa secara acak sampai terjadi kontak dengan mangsa. Hal yang sama juga diungkapkan oleh Krips et al. (1999), yang menyatakan bahwa $P$. persimilis melakukan pencarian mangsa secara acak. Dari hasil pengamatan dalam penelitian ini, imago betina $N$. californicus cenderung lebih aktif dan lebih banyak bergerak dibandingkan dengan deutonimfanya. Hal ini diduga menyebabkan imago betina $N$. californicus bisa menemukan mangsa dalam waktu yang lebih singkat dibandingkan dengan deutonimfanya. Secara umum waktu pencarian mangsa oleh imago betina dan deutonimfa $N$. californicus semakin cepat dengan meningkatnya kepadatan mangsa yang diberikan. Semakin tinggi kerapatan populasi mangsa, semakin tinggi pula peluang predator bertemu dengan mangsanya. Krips et al. (1999) menyatakan bahwa rata-rata pemangsaan bergantung pada rata-rata pertemuan antara predator dengan mangsanya dan motivasi predator untuk memangsa mangsa yang ditemuinya. Tingkat kelaparan mempengaruhi rasio pertemuan dan penangkapan mangsa (McMurty \& Rodriguez 1987). Perlakuan pemuasaan selama 24 jam menstimulasi kecepatan pencarian mangsa Amblyseius largoensis (MUMA), tetapi ketika dilaparkan selama 48 jam rata-rata kecepatan pencarian mangsa menurun sekitar 50\% (McMurty \& Rodriguez 1987).

Pada penelitian ini, baik deutonimfa maupun imago $N$. californicus diketahui memangsa sesamanya. Menurut Agarwala \& Dixon (1992), pada saat jumlah mangsa tidak dapat memenuhi 
kebutuhan konsumsi predator maka predator akan memangsa predator lain dari jenisnya sendiri. Dari penelitian ini juga diketahui bahwa jumlah deutonimfa $N$. californicus yang dimangsa sesamanya lebih tinggi dibandingkan dengan imago. Hal ini menunjukkan fase deutonimfa memiliki potensi kanibalisme yang lebih tinggi dibandingkan dengan fase imago betina $N$. californicus. Kanibalisme pada N. californicus dapat terjadi antar stadia yang sama maupun berbeda. Jika deutonimfa dipelihara bersama dengan imago betina, akan terjadi kanibalisme, khususnya pemangsaan deutonimfa oleh imago betina $N$. californicus.

\section{KESIMPULAN}

Deutonimfa dan imago betina $N$. californicus lebih memilih telur dibandingkan dengan nimfa TLK. Tingkat konsumsi imago betina $N$. californicus lebih tinggi dibandingkan dengan deutonimfanya. Semakin tinggi kerapatan telur TLK, semakin banyak yang dikonsumsi imago betina dan deutonimfa $N$. californicus. Semakin tinggi kerapatan telur TLK yang diberikan, semakin banyak telur yang diletakkan oleh imago betina $N$. californicus. Waktu pencarian mangsa oleh imago betina $A$ californicus lebih cepat dibandingkan dengan deutonimfanya. Peningkatan kepadatan predator meningkatkan jumlah predator yang dimangsa sesamanya. Kanibalisme pada $N$. californicus dapat terjadi baik pada deutonimfa, maupun imago betina.

\section{UCAPAN TERIMA KASIH}

Ucapan terima kasih disampaikan kepada PT. Strawberindo Lestari yag sudah mengijinkan menggunakan $N$. californicus sebagai bahan penelitian.

\section{DAFTAR PUSTAKA}

Agarwala BK, Dixon AFG. 1992. Laboratory study of cannibalism and interspecific predation in ladybird. Ecology Entomology 17:303-309. doi: http://dx.doi.org/10.1111/j.1365-2311.1992. tb01062.x.

Canlas LZ, Amano H, Ochiai N, Takeda M. 2006. Biology and the predation Japannese strain of Neoseiulus californicus McGregor (Acari: Phytoseiidae). Sistematic and Applied Acarology 11:141-157. Available at: http/: www.fcla.edu/ FlaEnt/fe84p602.pdf [accessed 21 Juli 2007].

Dixon AFG. 2000. Insects Predator-Prey Dinamics Ladybirds Beetles and Biological Control. London: Cambridge University Press.

Gotoh T, Nozawa M, Yamaguchi K. 2004. Prey consumption and functional response of three acarophagous species to eggs of the two-spotted spider mite in laboratory. Applied Entomology and Zoology 39:97-105. doi: http://dx.doi. org/10.1303/aez.2004.97.

Hassel MP. 1978. The Dynamics of Arthropod Predator Prey Systems. New York: Pricenton University Press.

Holling CS. 1961. Principles of insect predation. Annual Review of Entomology 6:163-182. doi: http://dx.doi.org/10.1146/annurev.en.06.010161. 001115.

Katayama H, Masui S, Tsuchiya M, Tatara A, Doi M, Kaneko S, Saito T. 2006. Density suppression of the citrus red mite Panonychus citri (Acari: Tetranychidae) due to the occurrence of Neoseiulus californicus (McGregor) (Acari: Phytoseiidae) on Satsuma mandarin. Applied Entomology and Zoology 41:679-684. doi: http:// dx.doi.org/10.1303/aez.2006.679.

Huffaker CB, Messenger PS. 1976. Theory and Practice of Biological Control. New York: Academic Press.

Krips OE, Kleijn PW, Willems PEL, Gols GJZ, Dicke M. 1999. Leaf hairs influence searching efficiency and predation rate of the predatory mite Phytoseiulus persimilis Athias-Henriot (Acari: Phytoseiidae). In: Bruin J, Van der Greest LPS, Sabelis MW (Eds.), Proceedings of the 3rd Symposium of the European Association of Acarologists (Ámsterdam, 1-5 Juli 1996). pp. 389-398. London: Kluwer Academic Publishers.

McMurty JA, Rodriguez JG. 1987. Nutritional ecology of phytoseiidae mites. In: Slansky FJR, Rodriguez JG (Eds.), Nutritional Ecology of Insects, Mites, Spiders, and Related Invertebrates. pp. 609-644. New York: Jhon Wiley and Sons.

ToyoshimaS, Hinomoto N. 2004. Intraspesific variation of reproductive characteristic of Neoseiulus californicus McGregor (Acari: Phytoseiidae). Applied Entomology and Zoology 39:351-355. doi: http:// dx.doi.org/10.1303/aez.2004.351.

Zhang ZQ. 2003. Mites of Greenhouses: Identification, Biology and Control. Walingford: CABI Publishing. doi: http://dx.doi.org/10.1079/ 9780851995908.0000. 